\title{
EXPERIMENTAL AND NUMERICAL INVESTIGATION OF AN AIR-TO-WATER HEAT PIPE-BASED HEAT EXCHANGER
}

\author{
H. Mroue ${ }^{1}$, J.B. Ramos ${ }^{1}$, L.C. Wrobel ${ }^{2}$, H. Jouhara ${ }^{*}, 1$ \\ ${ }^{1}$ Institute of Energy Futures, RCUK Centre for Sustainable Energy Use in Food Chains (CSEF), \\ ${ }^{2}$ Institute of Materials and Manufacturing
}

College of Engineering, Design and Physical Sciences, Brunel University London, Uxbridge UB8 3PH, UK, Tel.: +44 1895 267805; Fax: +44 1895 269777, Email: hussam.jouhara@brunel.ac.uk *Corresponding author

\begin{abstract}
An experimental and analytical investigation was conducted on an air-to-water heat exchanger equipped with six wickless heat pipes (thermosyphons) charged with water as the working fluid. The flow pattern consisted of a double pass on the evaporator and condenser sections. The six thermosyphons were all made from carbon steel, measured $2 \mathrm{~m}$ in length and were installed in a staggered arrangement.

The objectives of the reported experimental investigation were to analyse the effect of multiple air passes at different air inlet temperatures $\left(100\right.$ to $\left.250^{\circ} \mathrm{C}\right)$ and air mass flow rates $(0.05$ to $0.14 \mathrm{~kg} / \mathrm{s})$ on the thermal performance of the heat exchanger unit including the heat pipes. The results were compared with a CFD model that assumed the heat pipes were solid rods with a constant conductivity. The conductivity of the pipes was extracted from modifications of correlations available in the literature based around the theory of Thermal Resistance. The results proved to be very accurate within $10 \%$ of the experimental values.
\end{abstract}

keywords: heat pipe, thermosyphon, heat exchanger, CFD, Effectiveness

\section{Introduction}

Heat pipe-based heat exchangers are finding increased usage in a variety of applications due to new environmental policies to reduce exhaust temperatures and the carbon footprint of many industries [1;2]. These devices uniqueness derives from the use of heat pipes, responsible for increasing the heat exchanger's reliability, flow separation, ease of operation, system efficiency and reducing the overall manufacturing and maintenance cost. A heat pipe is essentially a superconductor [3], consisting of a sealed and evacuated tube partially filled with a working fluid. The working fluid is responsible for the device's high heat transfer capabilities as when faced with a temperature difference it enters a state of evaporation/condensation, allowing large quantities of heat to be transferred at an essentially constant temperature.

Heat pipe-based heat exchangers find use in a wide variety of industries, such as space [4], computing and electronics [5], ventilation and air conditioning (including dehumidification devices) [6], solar energy systems [7], water desalination [8], and nuclear systems [8;9], from temperatures below zero degrees [10], to as high as $950^{\circ} \mathrm{C}$ [11], depending on the materials composing the pipe and the working fluid used.

The basic operation of a wickless heat pipe (thermosyphon) relies upon a difference in temperature between both ends of the pipe. Upon coming into contact with a heat source, the working fluid inside the pipe evaporates, transporting the heat to the top of the pipe. When this vapour makes contact with the cooler wall of the pipe at the top, it condenses, releasing its latent heat and changing phase to 
liquid that will flow back to the evaporator due to the gravity effect to complete the working cycle [12].

There is a particular characteristic that can change a heat pipe's working principle and that is the existence or lack of a wick structure. Heat pipes that are used in the thermal management of electronic components have a built-in wick structure that allows them to work against the force of gravity, due to capillary pressure being exerted on the fluid. Heat pipes applied in industrial heat exchangers are devoid of a wick in order to keep costs. A schematic of a wickless heat pipe can be seen in Figure 1. Wickless heat pipes are technically named two-phase closed thermosyphons or gravity-assisted heat pipes and are the ones used in the experiment described in this paper.

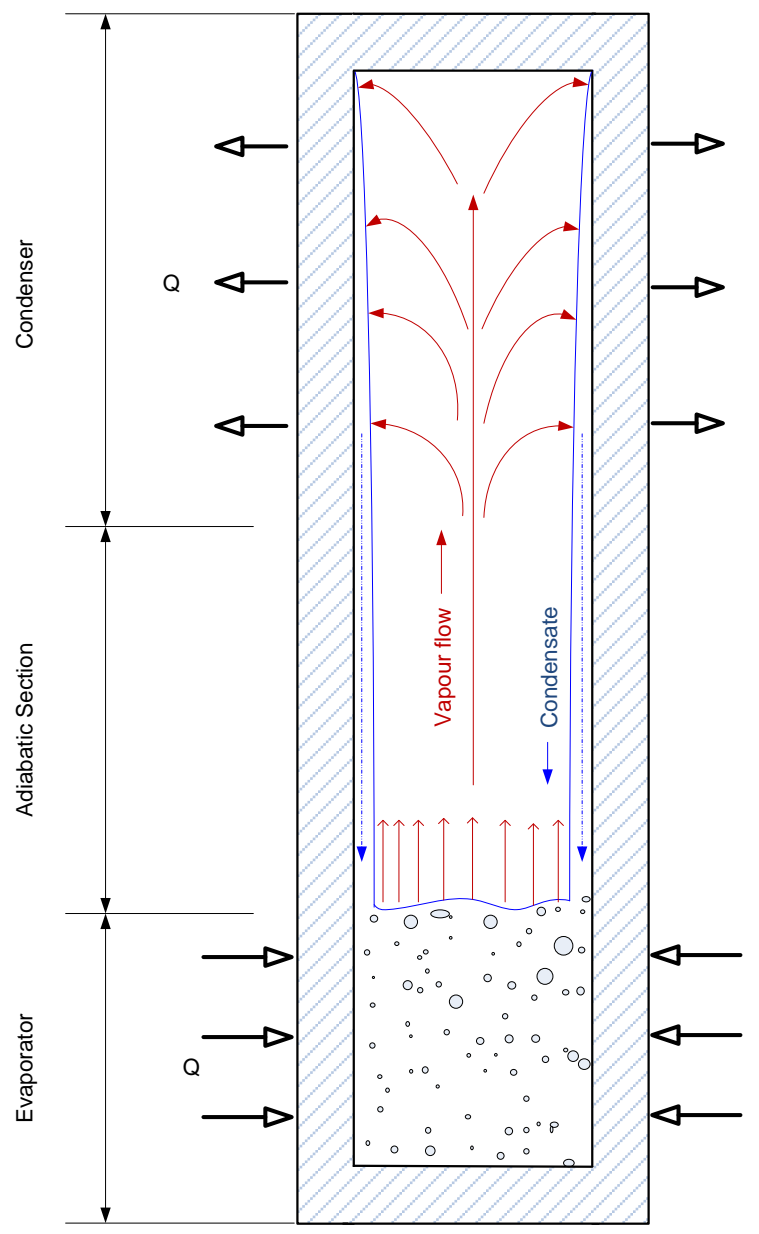

Figure 1 - Schematic of a working two-phase closed thermosyphon.

The heat exchanger under study is equipped with two phase closed thermosyphons which involves two air passes across the evaporator and two water passes using a baffle at the condenser side. A heat pipe-heat exchanger is usually divided in three parts: evaporator, adiabatic section and condenser, which coincide with the parts of the heat pipe as can be seen in Figure 1. In the evaporator of the heat exchanger under investigation, the hot air passes through the pipes, in the evaporator section, twice in what is effectively called "two passes", as can be seen in Figure 2. One of the advantages of having two passes in the evaporator section is to balance the heat pipes' working temperatures as the hot air will go through the first half of the evaporator and then cover the second half but by contacting the later rows first. This will lead to more balanced working temperatures inside the thermosyphons throughout the heat exchanger. In addition, and for the same hot air mass flow rate, forcing the hot air to flow through two passes will lead to higher convective heat transfer coefficient from the air to the 
pipes when compared with the lower velocity hot air if it passes through the pipes in one pass. The same enhancement in the heat transfer coefficient is achieved in the water side by using a baffle to allow the water to flow around the condenser ends of the thermosyphons faster (see Figure 3); hence higher convective heat transfer coefficient from the condenser to the water flow [13]. In order to determine the heat transfer coefficient on the shell sides, there are widely accepted correlations derived from empirical studies, as noted by Incropera \& DeWitt [14]. The flow in the condenser section makes contact with the pipes linearly and according to the numbering of the pipes, as seen in Figure 3.

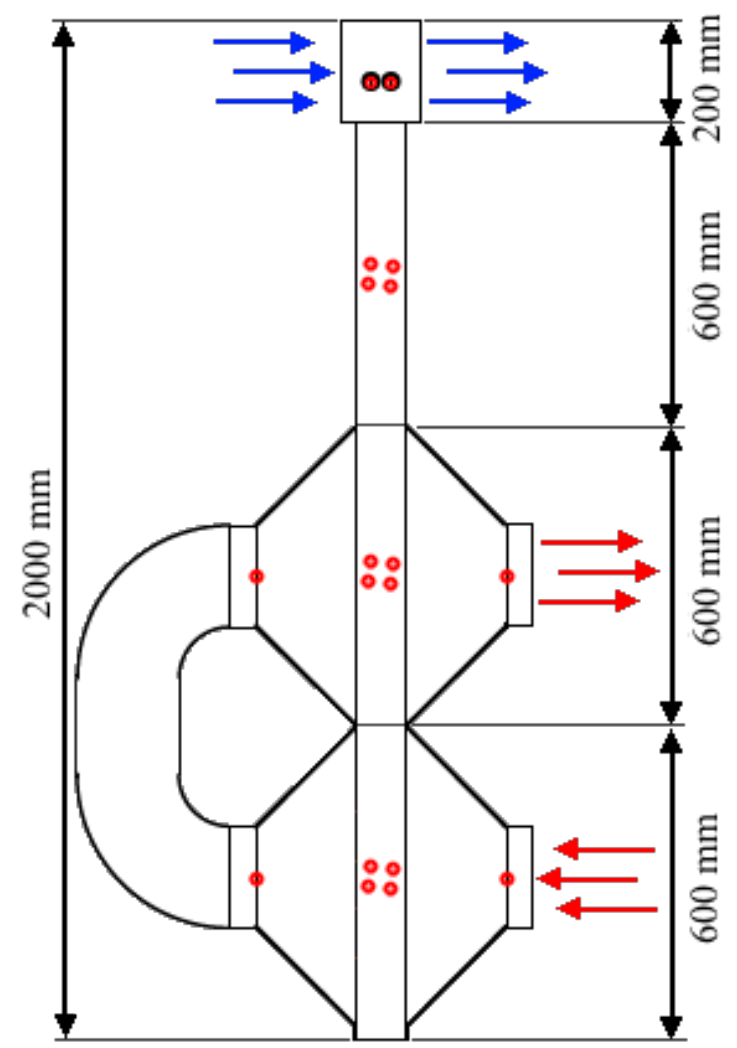

Figure 2 - Schematic representation of the heat pipe heat exchanger thermocouple locations (each red dot represents a Ktype thermocouple) and dimensions (all in mm). 


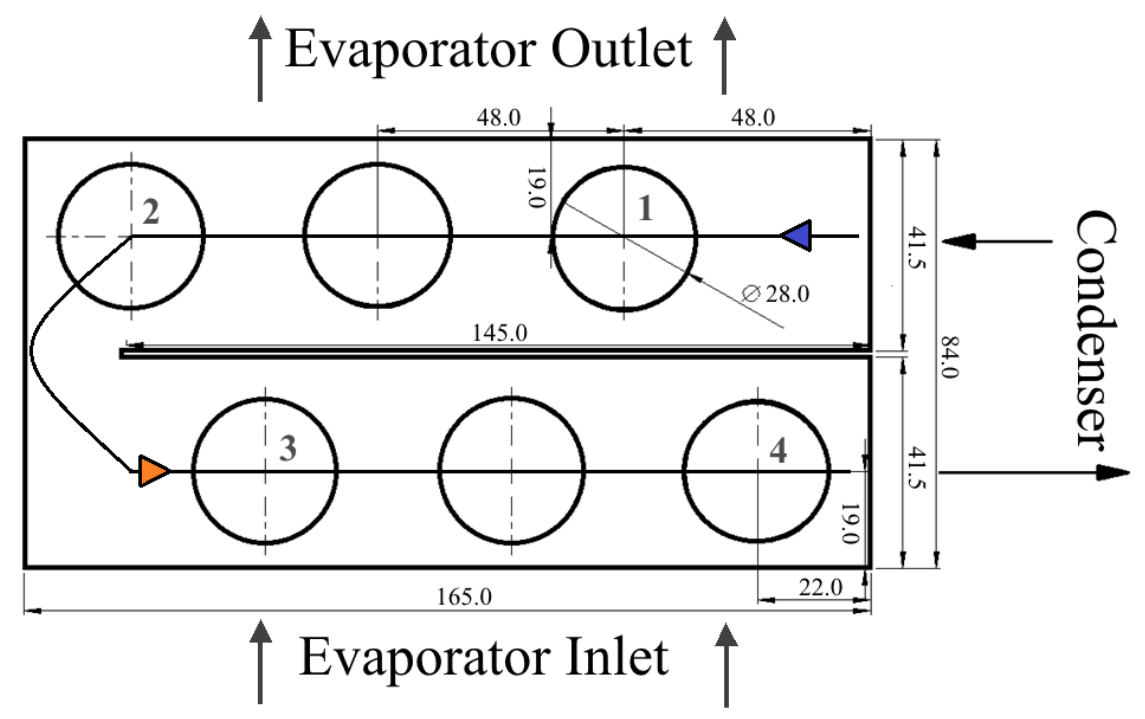

Figure 3 - Top down view of a cross section of the condenser section. The pipes numbered are the pipes with thermocouples on their surface.

Danielewicz et al. [15] have conducted an investigation of an air-to-air heat exchanger and produced a correlation which allowed the prediction of multiple variables related to heat exchanger performance based on the inlet conditions. A similar principle was used in this investigation; the experimental results were compared and validated through Computational Fluid Dynamics. Jouhara and Merchant [16] have also conducted an experimental study of a gas-to-air heat pipe-based heat exchanger of similar design, demonstrating the effect of different flow rates on the effectiveness of the heat exchanger.

In this paper, an air to water thermosyphon-based heat exchanger is investigated where both the hot and cold streams are flowing through two-shell passes across the evaporator and condenser sections of the thermosyphons bundle. In addition, an experimentally-validated numerical modelling to simulate the heat transfer process through the considered system is also reported.

\section{Test facility design}

The design of the test unit under study (shown in Figure 4) was based on a real heat exchanger unit currently in use albeit at a smaller scale. The system was equipped with six thermosyphons arranged vertically in two rows of three pipes each. Prior to filling and sealing the thermosyphons, the six carbon steel thermosyphons went through a vigorous internal surface modification to enable the compatibility of carbon steel with water as the working fluid. The process that was done on the pipe internal wall is referred to as passivation and is well described by Reay et al [17] where the oxidation the inside surface of the pipe was achieved with superheated steam vapour during the charging process. The passivation process prevents the chemical interaction between the carbon steel wall and the water that undergoes continuous boiling/condensation cycles during operation and ensure prolonged operating life of the carbon steel thermosyphon [17]. The experimental rig was divided in two circuits: the heat source consisted of a closed air circuit located in the lower part of the heat exchanger whereas the heat sink was an open-ended water circuit located at the top of the heat exchanger, as can be seen in Figure 5. 


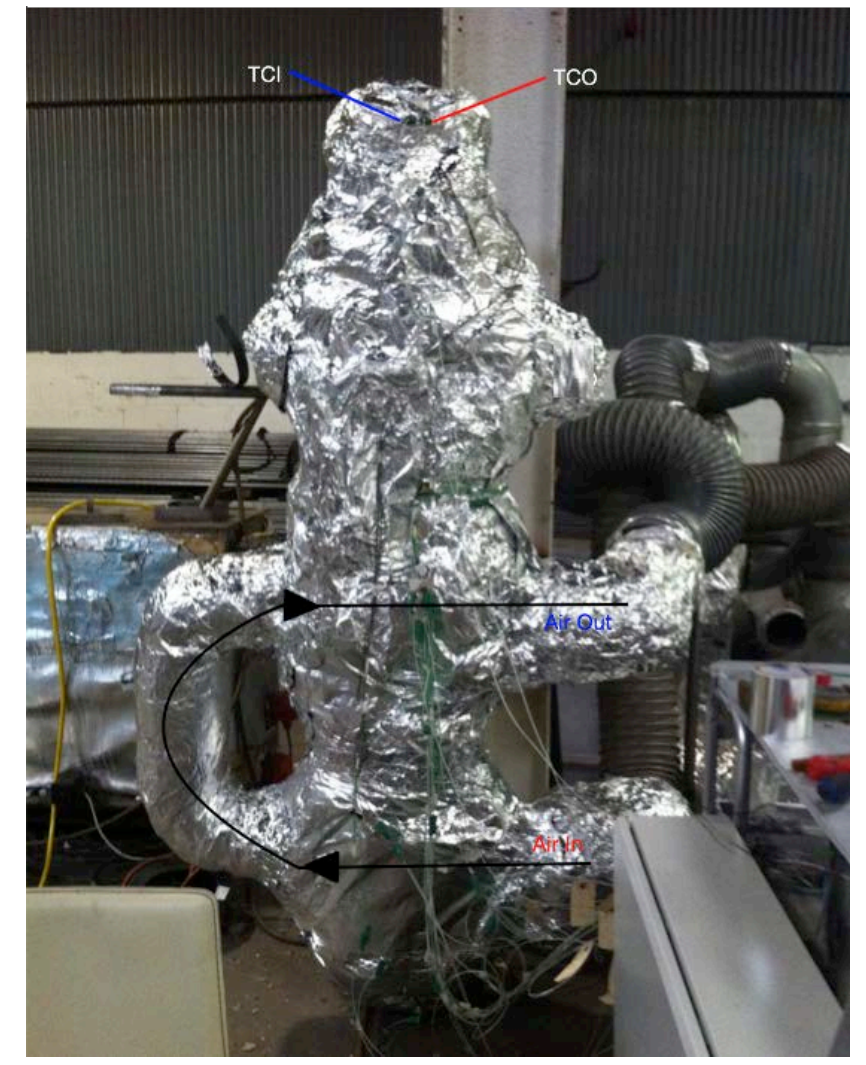

Figure 4 - Actual test rig used for testing.

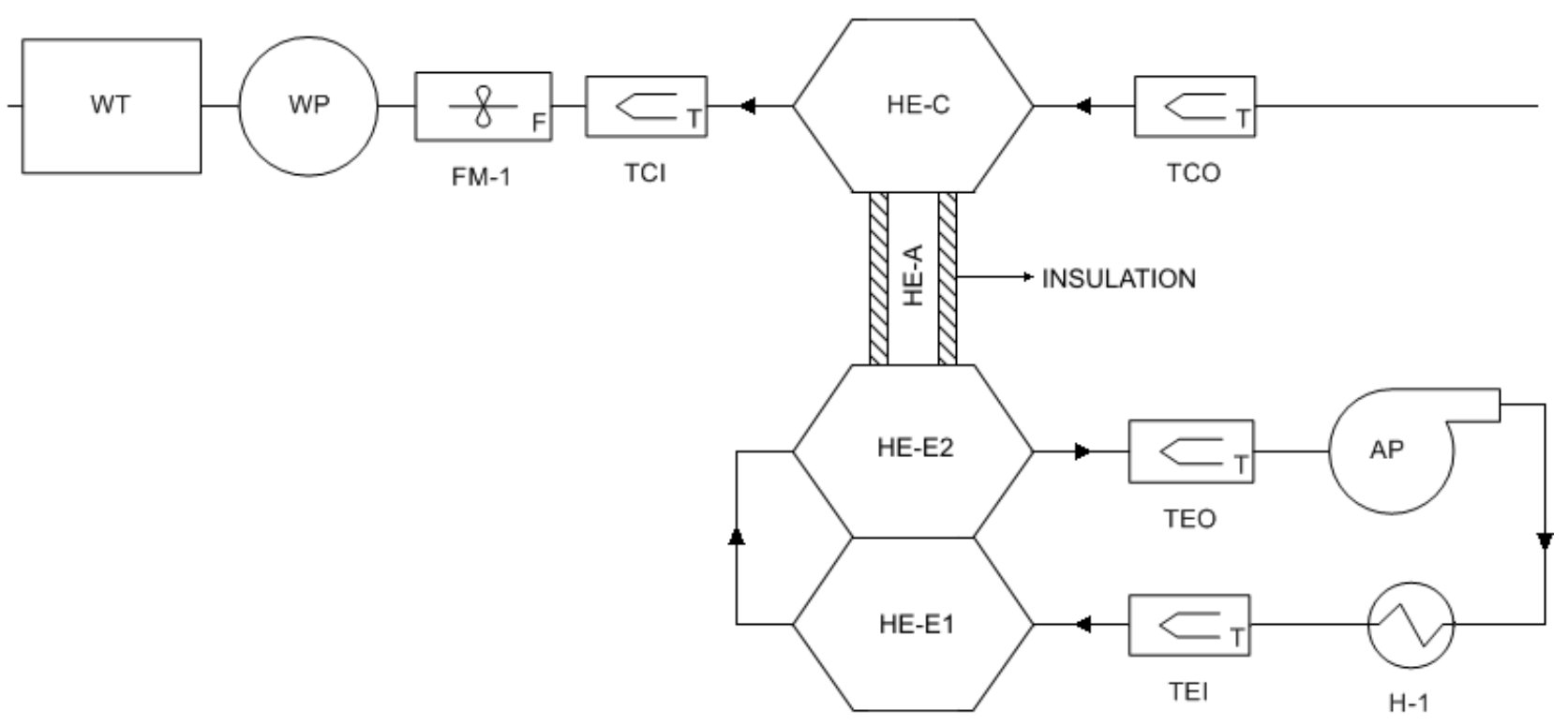

Figure 5 - Schematic drawing of the Heat Exchanger: WT-Water Tank, WP-Water Pump, FM-Flow Meter, TCIThermocouple Condenser Inlet, TCO-Thermocouple Condenser Outlet, AP-Air Pump, H-Heater, TEI-Thermocouple Evaporator Inlet, TEO-Thermocouple Evaporator Outlet, HE-Heat Exchanger, A-Adiabatic, C-Condenser, E-Evaporator.

The mass flow rate of the air circuit was controlled by a centrifugal fan, which forced the air through a heater and into the heat exchanger. The heater's power was controlled by a feedback system receiving data from a thermocouple placed at the inlet of the first evaporator section. The hot air then travelled through both evaporator sections and was then led back into the fan, closing the cycle. 
The cold water circuit was kept at a constant flow rate and temperature, controlled by a constant water head on the water tank and the temperature by a small cooler located within the tank.

K-type thermocouples were placed at the inlet and outlet of each air pass and water pass to measure the temperature of the fluid. A total of 22 thermocouples were placed in specific locations within the evaporator, adiabatic and condenser sections (see Figure 2). The thermocouples were connected to a data-logging device to gather information of the flow temperature behaviour within the heat exchanger unit.

There was a thermocouple installed at the inlet and outlet of each section, four in the evaporator section as two were needed for each "pass". In addition, there were two thermocouples on the surface of each pipe at the evaporator section, one in the adiabatic section and one in the condenser section.

\section{Test piece design}

When characterising heat pipes and consequently heat pipe heat exchangers, it is customary to divide them into three separate sections: evaporator, adiabatic section and condenser. The evaporator section comprises the hot air circuit where heat is added to the system, the condenser section includes the water circuit and serves as the heat sink, and the adiabatic section is simply the insulated area in the middle of both where, theoretically, no heat transfer takes place.

The unit under investigation was equipped with six thermosyphons arranged vertically. The heat pipes were made of carbon steel and each measured $2 \mathrm{~m}$ with a diameter of $28 \mathrm{~mm}$. The average wall thickness of the pipes was $2.5 \mathrm{~mm}$ giving them an average inner diameter of $23 \mathrm{~mm}$. The heat pipes were chemically treated from inside to prevent corrosion from the working fluid and then filled with distilled water to half the volume of the evaporator section.

The evaporator part of the heat exchanger was divided into two sections each spanning $0.6 \mathrm{~m}$ of the pipe's length. As the hot air entered the heat exchanger, it flowed over the lower $0.6 \mathrm{~m}$ of the pipes. Then it was led through two 90 degree bends to come back in between $0.6 \mathrm{~m}$ and $1.2 \mathrm{~m}$ of the bottom of the heat exchanger, making contact with the surface of the pipes in that location. Taking into account the pipes were filled to $50 \%$ of the total evaporator length, the double hot air pass allows the investigation of the heat transfer performance on the pool boiling and on the film condensate at the inner walls of the heat pipe. Each "pass" measured $0.6 \mathrm{~m}$, the first physically displayed under the second, as can be seen in Figure 2.

The condenser section was located on the top of the heat exchanger, occupying exactly $0.2 \mathrm{~m}$ and sweeping the 6 heat pipes one by one.

It was observed that the temperature measured at the adiabatic section of the heat pipe coincided with the value for the saturation temperature of the working fluid. The thermocouples located on the outer surface of the adiabatic section of selected heat pipes allowed the reading of the saturation temperature of that particular heat pipe. They were placed at exactly $1.5 \mathrm{~m}$ from the bottom of the unit (Figure 2).

\section{Operational procedure}

The performance of the test rig was monitored for an average of one hour of steady state per combination of mass flow rate and temperature. Only two parameters were varied during the experiment: the inlet air temperature and the mass flow rate. In the evaporator side, the air inlet temperature was controlled by the heater and varied between $100^{\circ} \mathrm{C}$ and $250^{\circ} \mathrm{C}$ at $50^{\circ} \mathrm{C}$ increments 
while the mass flow rate was controlled by the fan frequency which varied between $0.05 \mathrm{~kg} / \mathrm{s}$ and 0.14 $\mathrm{kg} / \mathrm{s}$ at $0.03 \mathrm{~kg} / \mathrm{s}$ increments.

In the condenser side, the water inlet temperature and flow rate were kept constant throughout the experiments. The water was kept at an average temperature of $14^{\circ} \mathrm{C}$ and the mass flow rate was kept at an average of $0.08 \mathrm{~kg} / \mathrm{s}$.

\section{CFD Boundary Conditions}

ANSYS Fluent was used to develop a numerical model to simulate the external heat flow over the pipes on both the air side (evaporator) and the water side (condenser). The model was developed in order to assess the efficiency of simulating the pipes as solid rods of constant conductivity for future heat exchanger modelling. For the model, the standard k-epsilon $(k-\varepsilon)$ turbulence model was used for all the tested results. The pressure-based coupled solver is the recommended choice as it offers a better result for a single-phase fluid flow, and is more consistent and efficient at steady-state [18].

The characteristics of the fluids in question (water and air) were based on standard tables of material properties [18]. The heat pipes were modelled as solid rods of conductivity $k$, a value derived from equations adapted from literature and described in detail in the next section. The inlet and outlet conditions for the heat exchanger can be seen in Table 1; boundary conditions of type "mass flow inlet" were used for both flows, with the outflow being in the opposite direction. For the air, the assumption was valid as it consisted of a closed circuit, so the air was being pulled out of the evaporator section at the outlet. Water is incompressible at normal atmospheric conditions and since the condenser had been completely purged of air, the flow at the outlet was safely assumed to be the same at the inlet, thus justifying the assumption. All the walls of the heat exchanger were considered to be adiabatic as they were well insulated in the experimental rig.

The CFD was run multiple times for each range of inlet conditions used in the experimental test.

Table 1 - Boundary Conditions.

\begin{tabular}{|l|c|c|c|}
\cline { 2 - 4 } \multicolumn{1}{c|}{} & Type & Mass flow rate $(\mathrm{kg} / \mathrm{s})$ & Temperature $\left({ }^{\circ} \mathrm{C}\right)$ \\
\hline Evaporator Inlet & Mass Flow Inlet & 0.05 to 0.14 at 0.03 intervals & 100 to 300 at 50 intervals \\
Evaporator Outlet & Outflow & - & Desired Output \\
\hline Condenser Inlet & Mass Flow Inlet & constant 0.08 & Varied between 13 and 14 \\
Condenser Outlet & Outflow & - & Desired Output \\
\hline
\end{tabular}

\section{Governing Equations}

The conductivity of the heat pipe $k$, as mentioned before, was derived from equations found in the literature; more specifically, from the resistance to heat transfer offered by the heat pipes within the heat exchanger (K/W). This total resistance to heat transfer may be represented by [19]:

$$
R_{T}=\frac{\Delta T_{L M}}{\dot{Q}_{t}}
$$


$\Delta T_{L M}$ represents the logarithmic mean temperature difference and $\dot{Q}_{T}$ the heat transfer rate (W). Equation (2) clearly shows that the total thermal resistance is an inverse to the total rate of heat transfer in a heat exchanger, represented below:

$$
\dot{Q}_{T}=U A_{T} \Delta T_{L M}
$$

$U$ represents the overall heat transfer coefficient $\left(\mathrm{W} / \mathrm{m}^{2} \mathrm{~K}\right), A_{T}$ the total heat surface area and $\Delta T_{L M}$ the Logarithmic Mean Temperature Difference.

In order to break down the total thermal resistance $\left(R_{T}\right)$ into all its constituent parts, an analogy to an electrical resistance ought to be done. The total resistance for a single heat pipe is a sum of the resistances for each mode of heat transfer:

$$
R_{h p}=\left(\frac{1}{R_{k, e}+R_{h, \text { film } b}}+\frac{1}{R_{k, e}+R_{h, \text { pool b }}}\right)^{-1}+R_{h p, \text { inner }}+R_{h, \text { condensation }}+R_{k, c}
$$

The subscript $h$ represents convection, $k$ conduction, $b$ boiling, $e$ evaporator and $c$ condenser. Nucleate film boiling and pool boiling take place in parallel while the other modes of heat transfer take place in series. The method to determine the internal resistances of the thermosyphon is made available by the Engineering Sciences Data Unit (ESDU) [20]. Considering that all the pipes in this particular configuration are 6 resistances in parallel, the total resistance will be:

$$
\frac{1}{R_{6 h p}}=\frac{1}{R_{1}}+\frac{1}{R_{2}}+\frac{1}{R_{3}}+\frac{1}{R_{4}}+\frac{1}{R_{5}}+\frac{1}{R_{6}}
$$

Assuming all the heat pipes have the same thermal resistance $\left(R_{h p}\right)$, the total thermal resistance offered by the six heat pipes can be determined from:

$$
R_{6 h p}=\frac{R_{h p}}{6}
$$

and the total thermal resistance of the heat exchanger becomes:

$$
R_{T}=R_{6 h p}+R_{h, e}+R_{c, e}
$$

Moving back to equation 3, in order to find the different values of resistance to complete the equation, the heat pipe is divided in at least 3 parts; the evaporator section, the condenser section and the adiabatic section. The evaporator section is further divided into a lower half and an upper half.

Inside the heat pipe, there are at least three different heat transfer mechanisms at work: pool boiling, nucleate film boiling and film condensation; pool boiling takes place in the first pass of the heat exchanger, film boiling on the second and film condensation on the condenser section. There are expressions available in the literature for each of these heat transfer mechanisms and some of them were adapted in order to better suit this application.

Looking at the evaporator section, the first heat transfer mode from the fluid to the pipe is made through convection and given by the general equation below, displaying the following resistances to heat transfer:

$$
\dot{Q}_{h}=h A \Delta T \quad \therefore \quad R_{h, e}=\frac{1}{h_{e} A_{e}} \quad \text { and } \quad R_{h, c}=\frac{1}{h_{c} A_{c}}
$$


where $h$ refers to the heat transfer coefficient $\left(\mathrm{W} / \mathrm{m}^{2} \mathrm{~K}\right)$ between the fluid and the solid surface, which in our case is air-carbon steel and water-carbon steel. The subscript $h$ refers to convection heat transfer. $A$ is the surface area or exposure $\left(\mathrm{m}^{2}\right)$ and $\Delta T$ the difference in temperature between the two.

Moving with the flow of heat the next barrier is the pipe wall, and heat is transferred by conduction, to which the general equation is the following:

$$
\dot{Q}_{k}=\frac{2 \pi k l \Delta T}{\ln \left(r_{\text {out }}-r_{\text {in }}\right)} \quad \therefore \quad R_{k}=\frac{\ln \left(r_{\text {out }}-r_{\text {in }}\right)}{2 \pi k l}
$$

where $k$ is the thermal conductivity, $L$ is the length of the pipe subjected to the two different flows, $r_{\text {out }}-r_{\text {in }}$ represent the tube thickness and $\Delta T$ is the difference in temperature between the inside and the outside of the pipe. This equation will be applied to the two evaporator sections and the condenser section. It is mainly affected by the area of exposure and the conductivity of the material.

The next heat transfer process is boiling, in which the heat travels from the pipe wall to the working fluid. This process essentially consists of pool boiling, whose correlation is given by Rohsenow [21]:

$$
\frac{\dot{q}}{A}=\mu \times h_{f g} \times \sqrt{\frac{g\left(\rho_{L}-\rho_{v}\right)}{\sigma}} \times\left(\frac{c_{p} \Delta T_{b}}{h_{f g} C_{s f}}\right)^{1 / m} \times \operatorname{Pr}^{-n / m}
$$

$C_{s f}$ is a constant for boiling, which changes in accordance to different surface materials and fluids. All thermophysical properties of the fluid are evaluated at the saturation temperature. $m$ and $n$ are constants, $m$ is generally $1 / 3, n$ is 1.0 for water and 1.7 for other fluids.

Looking at the second pass, there is also evaporation on the condensate flowing down to the evaporator. The heat transfer coefficient for nucleate film boiling is the following [22]:

$$
\frac{\dot{q}}{A}=1.155 \times 10^{-3} N u_{\mu f}^{0.33} \operatorname{Pr}_{l}^{0.35} K_{p}^{0.7}\left(q_{e} l_{m} /\left(\rho_{V} h_{f g} v_{l}\right)\right)^{0.7} \times \Delta T_{b} k / l_{l}
$$

where $K_{p}$ is a dimensionless parameter inverse to surface tension, $l_{m}$ the bubble length scale and $l_{l}$ the film thickness scale. Each equation is applied for each different surface area and the heat transfer to the top of the heat exchanger can be determined, assuming there are no heat losses at the adiabatic section as the fluid travels up and down the pipe. After getting to the top section, where the walls are cooler the fluid will condense, giving its latent energy to the wall. For this heat transfer, the laminar condensation from Nusselt is used [23]:

$$
h_{m}=0.943 \times\left(\frac{k_{L}^{3} \rho_{L}\left(\rho_{L}-\rho_{V}\right) g h_{f g}}{\mu_{l} \theta l}\right)^{1 / 4}
$$

McAdams [24] suggests that experimental values are often 20\% larger than theoretical values, and we can also assume that $\rho_{l} \gg \rho_{v}$ which simplifies our equation into:

$$
h_{m}=1.13 \times\left(\frac{k_{L}{ }^{3} \rho_{L}{ }^{2} g h_{f g}}{\mu_{l} \theta l}\right)^{1 / 4}
$$

\section{Heat Exchanger Effectiveness Model}

A numerical effectiveness model was developed based on the data gathered in order to predict the effectiveness of the heat exchanger. The effectiveness is the ratio of the actual heat transfer rate to the 
maximum theoretical heat transfer rate and it is determined from the following expression after the outlet conditions are known [25]:

$$
\varepsilon=\frac{\dot{Q}_{\text {actual }}}{\dot{Q}_{\max }}=\frac{C_{w}\left(T_{c, o}-T_{c, i}\right)}{C_{\min }\left(T_{\max }-T_{\min }\right)}=\frac{C_{w}\left(T_{c, o}-T_{c, i}\right)}{C_{\min }\left(T_{h, i}-T_{c, i}\right)}
$$

where $\dot{Q}$ represents the heat transfer rate, $C_{w}$ refers to the heat capacity rate for water (subscript $w$ ) and $C_{\min }$ represents the minimum heat capacity rate between the water side and the air side. $T_{C}$ refers to the condenser side and $T_{h}$ to the evaporator side.

The effectiveness determined through equation (12) can then be used to determine the heat transfer rate of the heat exchanger through the following expression:

$$
\dot{Q}=\varepsilon \cdot \dot{Q}_{\max }
$$

Going back to equation (12), the maximum heat extraction rate can be found by multiplying the minimum heat capacity rate by the maximum difference in temperature, which in this case is the difference between the inlet temperatures:

$$
\dot{Q}_{\max }=C_{\min }\left(T_{h, \text { in }}-T_{c, \text { in }}\right)
$$

Through manipulation of the above equation, the outlet temperatures can be predicted as follow:

$$
\begin{gathered}
T_{h, \text { out }}=T_{h, \text { in }}-\frac{\dot{Q}}{C_{h}} \\
T_{c, \text { out }}=T_{c, \text { in }}+\frac{\dot{Q}}{C_{c}}
\end{gathered}
$$

\section{Mesh selection}

Three meshing levels were generated: coarse, medium and fine (see Table 2). In the case of hexahedron or tetrahedron meshes, the maximum skewness should be lower than 0.7 , while in triangular elements, it must be less than 0.8 [18]. There was also inflation included around the pipes in order to better simulate the heat transfer between the pipes and the other volumes (see Figure 6).

Table 2 - Mesh Dependency.

\begin{tabular}{|c|c|c|c|c|}
\hline Level & No of Cells & Type of cells & Skewness & Time per iter. \\
\hline Coarse & 798,852 & Hex + Tetra & av: 28\%, stdev: $20 \%$ & $5-10 \mathrm{~s}$ \\
\hline Medium & $1,299,435$ & Hex + Tetra & av: 22\%, stdev: $13 \%$ & $7-15 \mathrm{~s}$ \\
\hline Fine & $2,948,489$ & Hex + Tetra & av: 22\%, stdev: $13 \%$ & $30-50 \mathrm{~s}$ \\
\hline
\end{tabular}




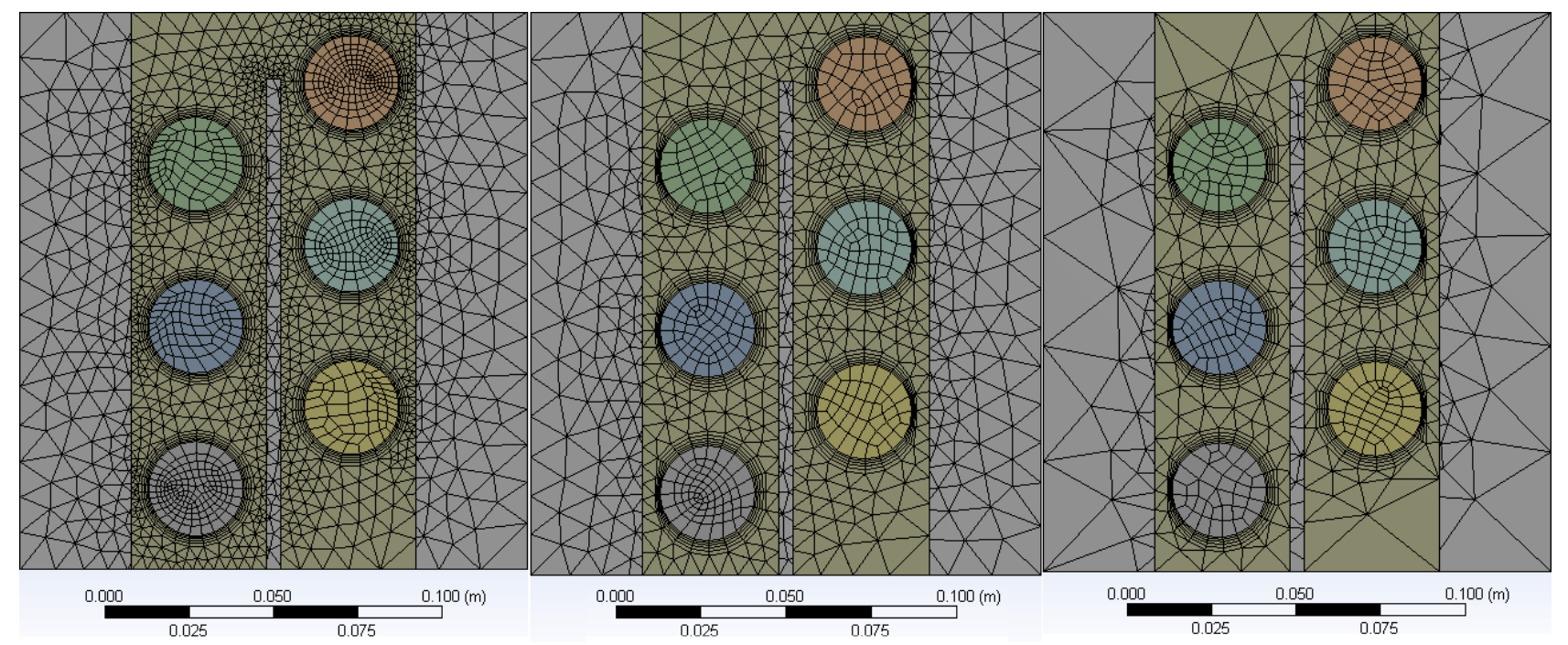

Figure 6 - Comparison between the three different meshes - Fine, Medium and Coarse, respectfully.

Two evaporator inlet conditions were considered for which the experimental results were compared to the simulated results. The results provided by the medium mesh were the most acceptable in the end taking into account the time taken until convergence is observed.

Table 3 - Mesh comparison (the percentage error is shown in brackets).

\begin{tabular}{|c|c|ccc|}
\hline Inlet Conditions: & $T_{\text {out }}$ Exp. & $T_{\text {out }}$ Fine Mesh & $T_{\text {out }}$ Medium Mesh & $T_{\text {out }}$ Coarse Mesh \\
\hline$T_{h, \text { in }}=250^{\circ} \mathrm{C}, \dot{m}_{h, \text { in }}=0.14 \mathrm{~kg} / \mathrm{s}$ & $205.0^{\circ} \mathrm{C}$ & $214.4^{\circ} \mathrm{C}(+4.6 \%)$ & $215.2^{\circ} \mathrm{C}(+5.0 \%)$ & $225.4^{\circ} \mathrm{C}(+9.9 \%)$ \\
\hline$T_{c, \text { in }}=14.8^{\circ} \mathrm{C}, \dot{m}_{c, \text { in }}=0.08 \mathrm{~kg} / \mathrm{s}$ & $33.1^{\circ} \mathrm{C}$ & $30.6{ }^{\circ} \mathrm{C}(-7.6 \%)$ & $30.4{ }^{\circ} \mathrm{C}(-8.1 \%)$ & $27.8^{\circ} \mathrm{C}(-16.0 \%)$ \\
\hline$T_{h, \text { in }}=150^{\circ} \mathrm{C}, \dot{m}_{h, \text { in }}=0.08 \mathrm{~kg} / \mathrm{s}$ & $124.9^{\circ} \mathrm{C}$ & $124.0^{\circ} \mathrm{C}(-0.7 \%)$ & $123.9^{\circ} \mathrm{C}(-0.9 \%)$ & $117.8^{\circ} \mathrm{C}(-5.6 \%)$ \\
\hline$T_{c, \text { in }}=14.8^{\circ} \mathrm{C}, \dot{m}_{c, \text { in }}=0.08 \mathrm{~kg} / \mathrm{s}$ & $21.9^{\circ} \mathrm{C}$ & $22.6^{\circ} \mathrm{C}(+3.1 \%)$ & $22.8^{\circ} \mathrm{C}(+4.1 \%)$ & $24.8^{\circ} \mathrm{C}(+13.5 \%)$ \\
\hline
\end{tabular}

The comparison between the meshes is laid out in Table 3 for two different inlet conditions. The first three rows represent the air inlet conditions at $250{ }^{\circ} \mathrm{C}$ and $0.14 \mathrm{~kg} / \mathrm{s}$, and the last three rows represent the air inlet conditions at $150{ }^{\circ} \mathrm{C}$ and $0.08 \mathrm{~kg} / \mathrm{s}$, the water inlet conditions are the same for both $\left(14.8^{\circ} \mathrm{C}\right.$ and $\left.0.08 \mathrm{~kg} / \mathrm{s}\right)$. The first column shows part of the inlet boundary conditions, the second column displays the outlet temperatures of the experimental test and the next three columns show the predicted CFD results for each different element sizing method.

The medium mesh was selected as the best alternative for all the CFD simulations due to the fact that the results were not much improved by refining the mesh. Regardless of this fact, it can be observed that all the flows appeared to extract more heat than in the experimental test. This is to be expected, taking into account the walls of the pipes in the adiabatic section of the CFD simulation were $100 \%$ adiabatic $(Q=0)$ whereas in real life there are always some differences in temperature even with the best possible insulation as was the case.

\section{Results and discussion}

A plot of the temperatures versus the mass flow rates was created to ensure the results were consistent. Figure 7, 8, 9 and 10 show the temperature of the flow at the inlets and outlets of the evaporator and condenser sections of the heat exchanger. It can be observed that the duty of the heat 
exchanger increases at higher mass flow rates and higher temperatures, shown by the greater difference in temperature in the water side at higher temperatures and mass flow rates.

At lower flow rates, the pipe is given more time to absorb the heat and that is reflected in an increase of the temperature difference across the evaporator, but as has been mentioned before, this does not reflect an increase in the duty or total heat transfer rate, shown in Figure 11.

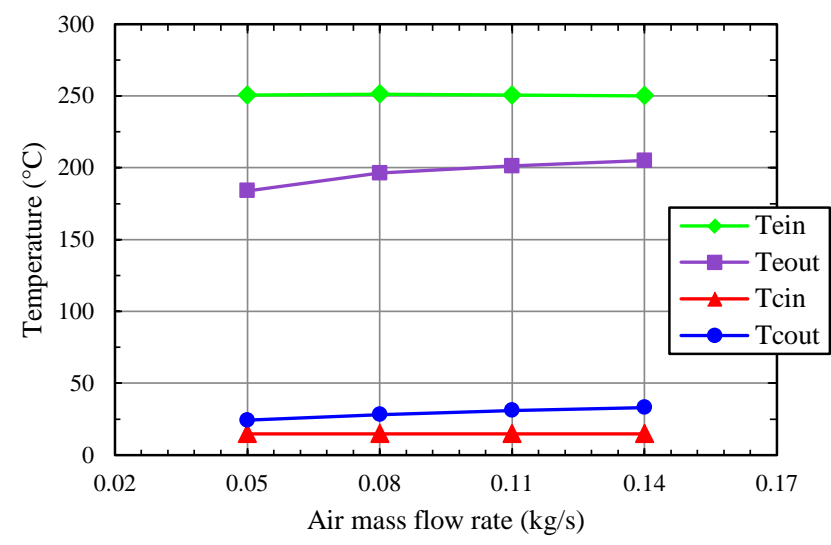

Figure 7 - Temperature distribution along the heat exchanger for $250{ }^{\circ} \mathrm{C}$ inlet temperature.

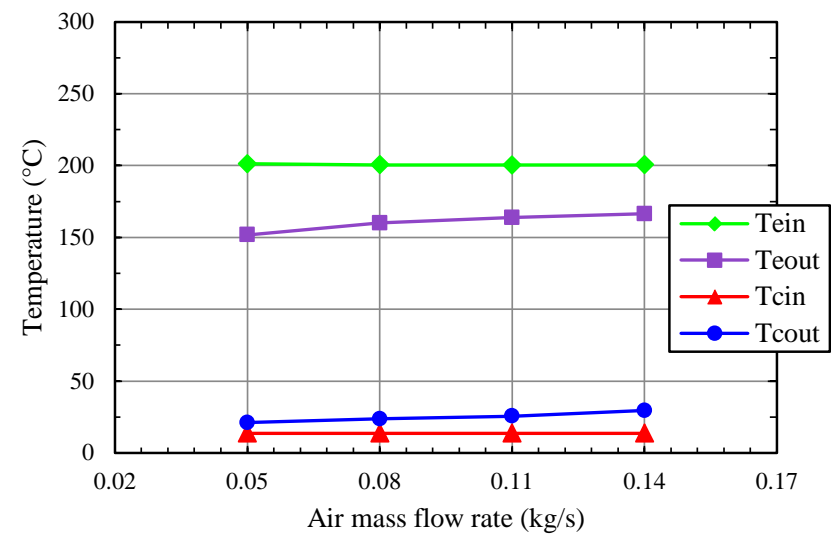

Figure 8 - Temperature distribution along the heat exchanger for $200{ }^{\circ} \mathrm{C}$ inlet temperature.

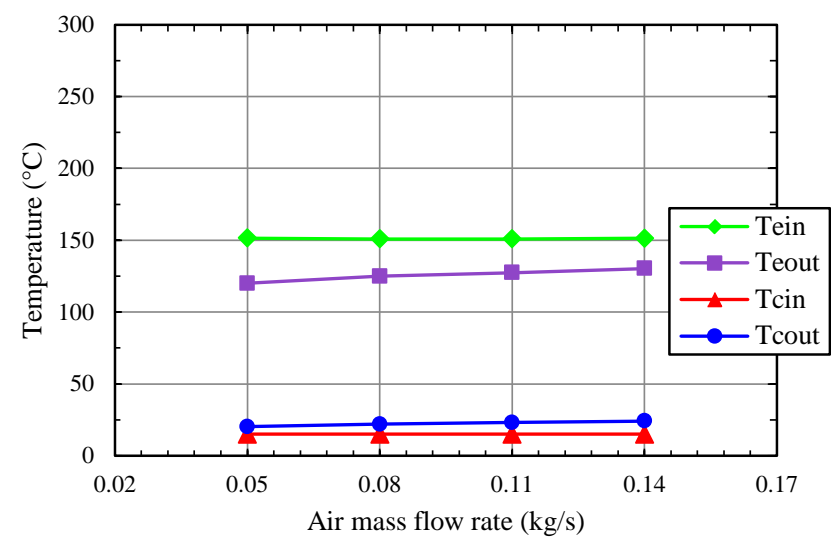

Figure 9 - Temperature distribution along the heat exchanger for $150^{\circ} \mathrm{C}$ inlet temperature. 


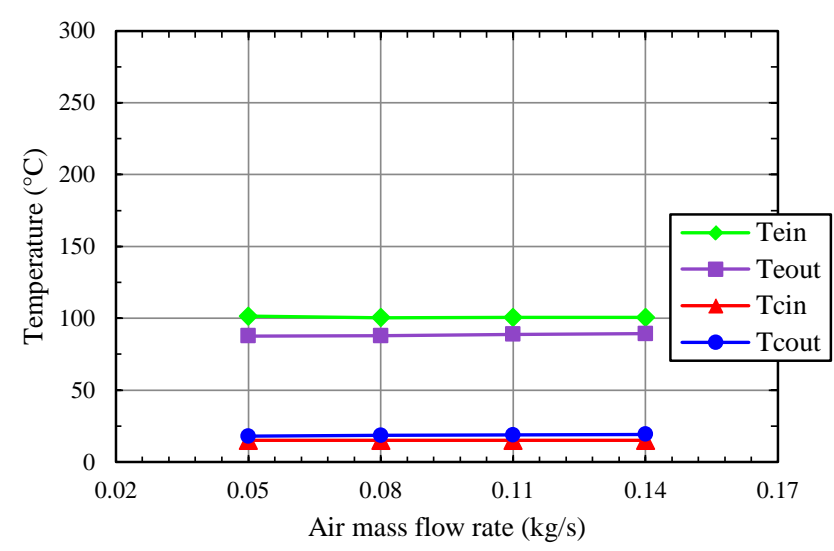

Figure 10 - Temperature distribution along the heat exchanger for $100^{\circ} \mathrm{C}$ inlet temperature.

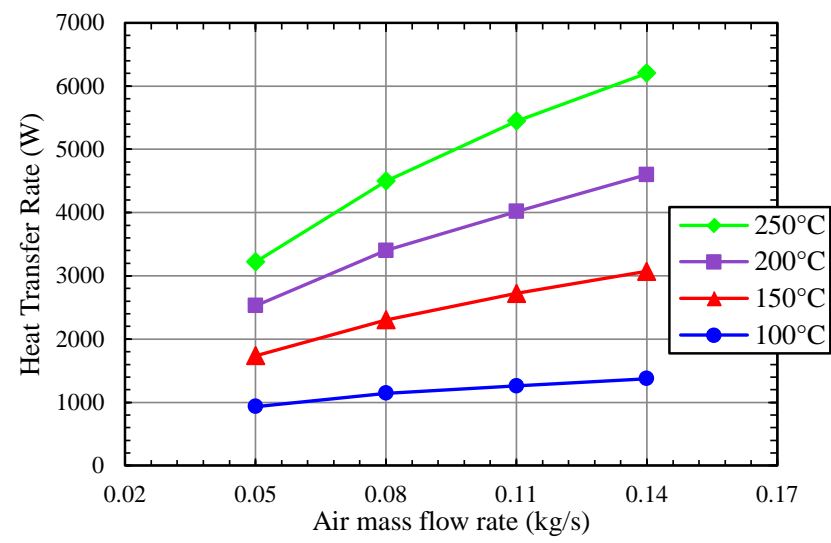

Figure 11 - Heat Transfer Rate of the Heat Exchanger according to the inlet conditions.

Figure 12 to Figure 15 compare the working temperature of the heat pipes for each inlet condition. The working temperature increases with the increase in mass flow rate and inlet temperature at the evaporator section, as expected. However, there is a difference in temperature between each individual pipe. The pipes were numbered in accordance to the diagram in Figure 5.

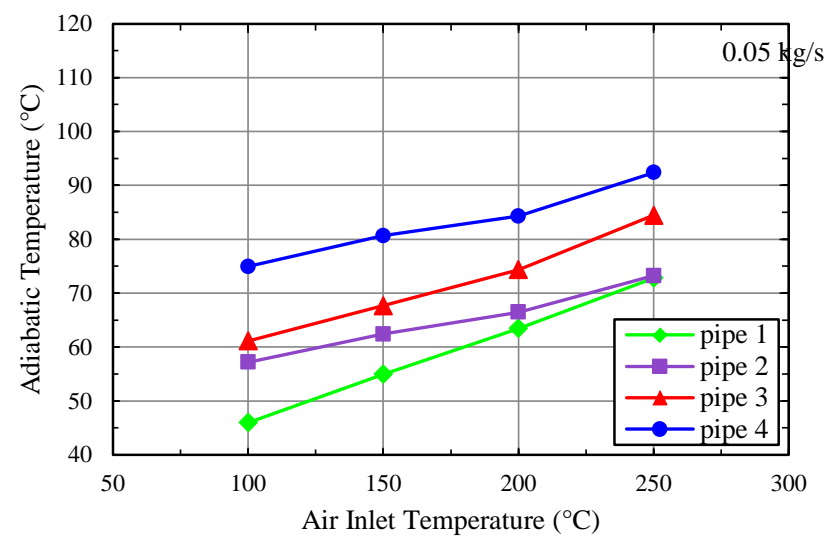

Figure 12 - Working temperature of each pipe for different inlet temperatures ( $\dot{\mathrm{m}}=0.05 \mathrm{~kg} / \mathrm{s}$ ). 


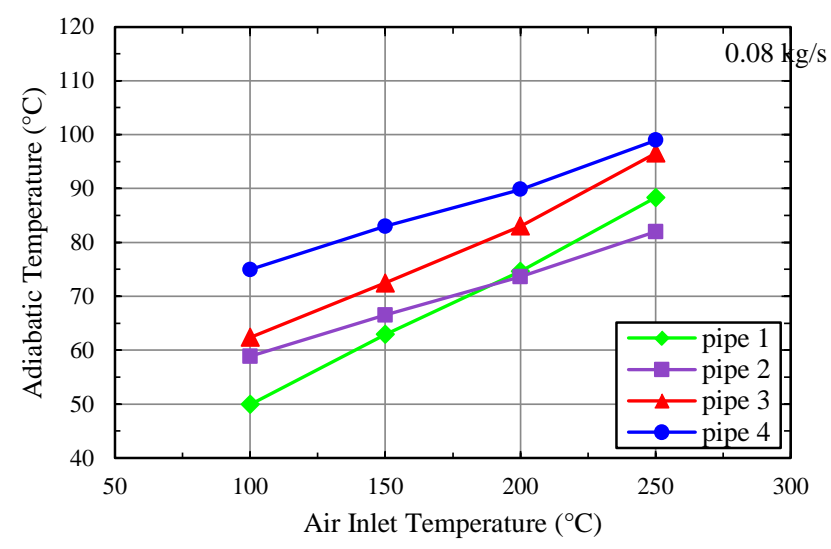

Figure 13 - Working temperature of each pipe for different inlet temperatures ( $\dot{\mathrm{m}}=0.08 \mathrm{~kg} / \mathrm{s})$.

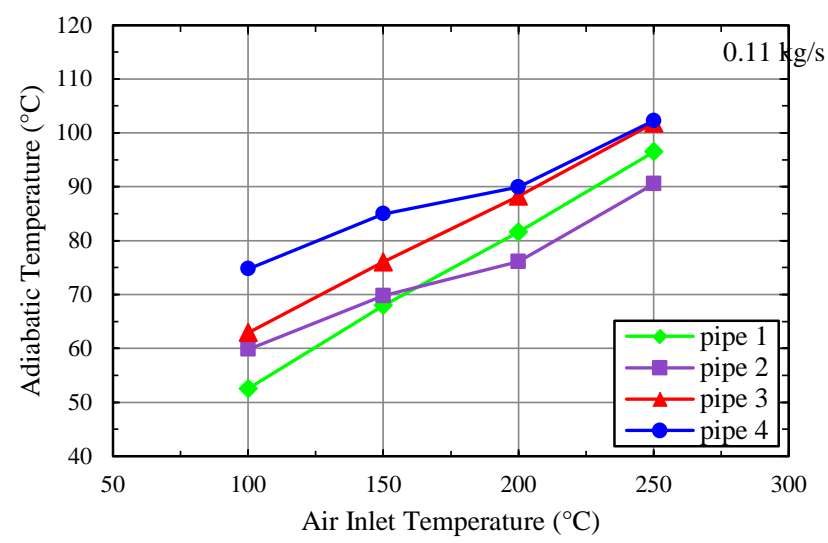

Figure 14 - Working temperature of each pipe for different inlet temperatures ( $\dot{\mathrm{m}}=0.11 \mathrm{~kg} / \mathrm{s})$.

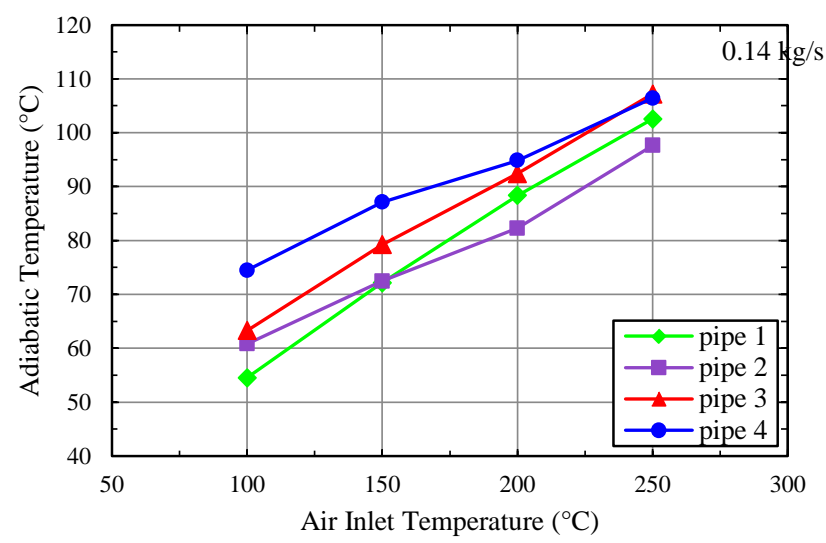

Figure 15 - Working temperature of each pipe for different inlet temperatures ( $\dot{\mathrm{m}}=0.14 \mathrm{~kg} / \mathrm{s}$ ).

It can be observed that the heat pipe with the highest average working temperature is pipe 4; it is located on the row of pipes that first make contact with the hot flow at the first pass and it is the heat pipe furthest away from the condenser inlet. After pipe 4, all the pipes follow in the inverse order to the condenser section, therefore 3 has the next highest average temperature, followed by 2 and 1 , the closest to the condenser inlet. Pipes 1 and 2 are located on the first row of the second pass in the evaporator section. 
With the increase in mass flow rate, the temperatures become more similar to one another but it can still be observed that the average working temperature of pipes 3 and 4 is higher at lower air inlet temperatures. This is due to a combination of factors. Firstly, as can be observed in Figure 5 and has been mentioned before, pipes 3 and 4 are on the first row that comes into contact with the evaporator inlet. Secondly, they are also located the farthest away to the condenser inlet, receiving warmer water at the condenser side, which results in a lower difference in temperature between the bottom and the top of the heat pipe.

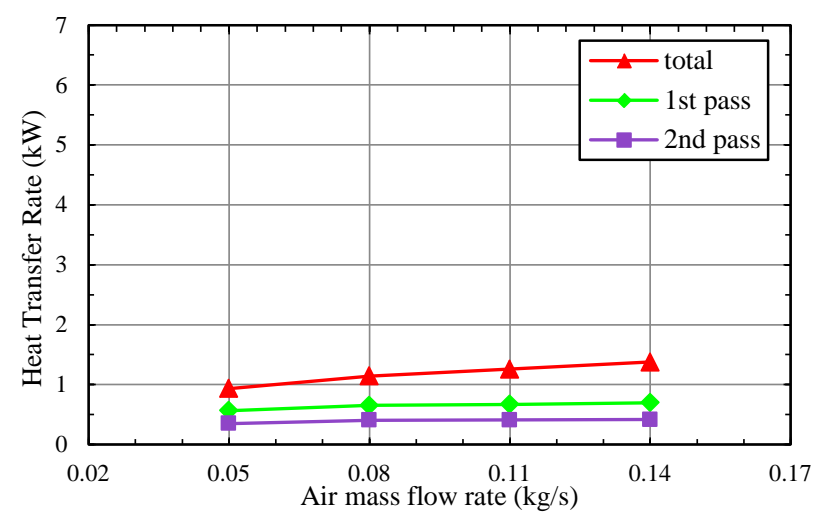

Figure 16 - Heat transfer rate for different flow rates at $100^{\circ} \mathrm{C}$ air inlet temperature

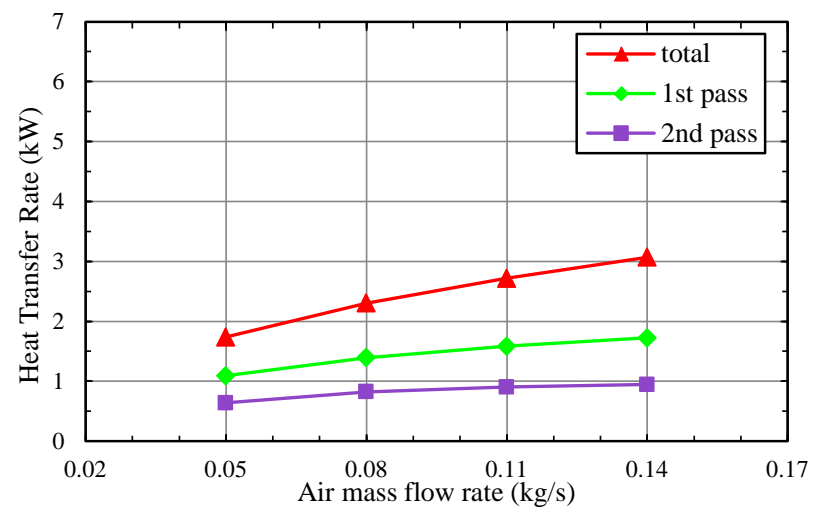

Figure 17 - Heat transfer rate for different flow rates at $150^{\circ} \mathrm{C}$ air inlet temperature

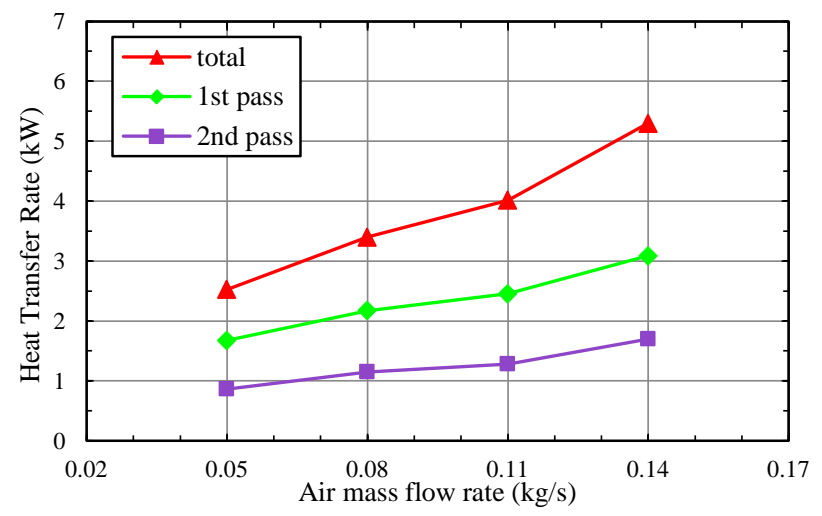

Figure 18 - Heat transfer rate for different flow rates at $200^{\circ} \mathrm{C}$ air inlet temperature 


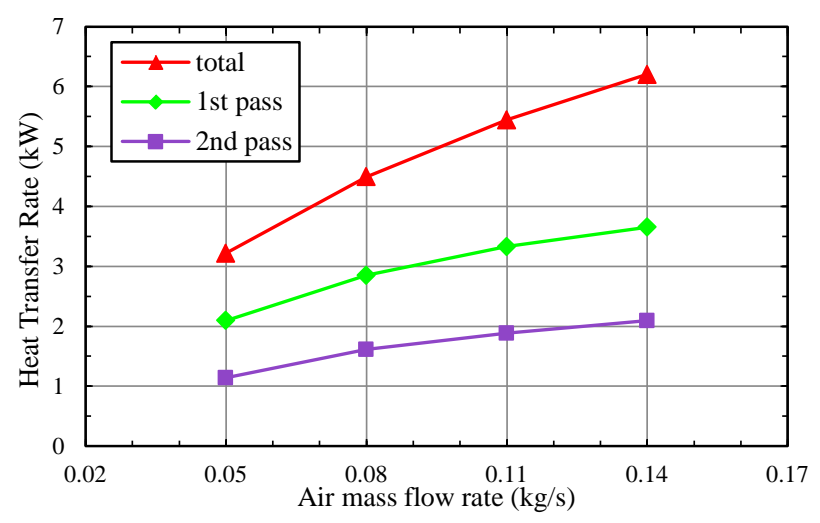

Figure 19 - Heat transfer rate for different flow rates at $250^{\circ} \mathrm{C}$ air inlet temperature

Figures 16, 17, 18 and 19 show the heat transfer rate (Q) across each air pass of the heat exchanger unit for each different inlet condition. "Total" represents the total heat transfer rate taking into account both air passes. The trend is for the temperature difference across the first pass to be larger than the second pass due to a higher difference in temperature between the incoming flow and the working temperature of the pipes, therefore higher heat transfer. Increasing the inlet air temperature results in a higher temperature difference across each pass and therefore an increase in the heat transfer rate. Likewise, increasing the mass flow rate increases the overall turbulence, also having the effect of increasing the overall heat transfer rate.

The effectiveness of the test unit (given by the variable $\varepsilon$ and in equation 12) was also determined according to the different inlet conditions and is displayed in Figure 20. The graph shows a good downward trend for different flow rates and temperatures except for $100^{\circ} \mathrm{C}$. This is caused by a lack of heat being absorbed by the pipe, causing irregularities in the boiling regime which results in poor performance. At lower mass flow rates the effectiveness is higher as the pipe has more time to absorb the heat in the flow.

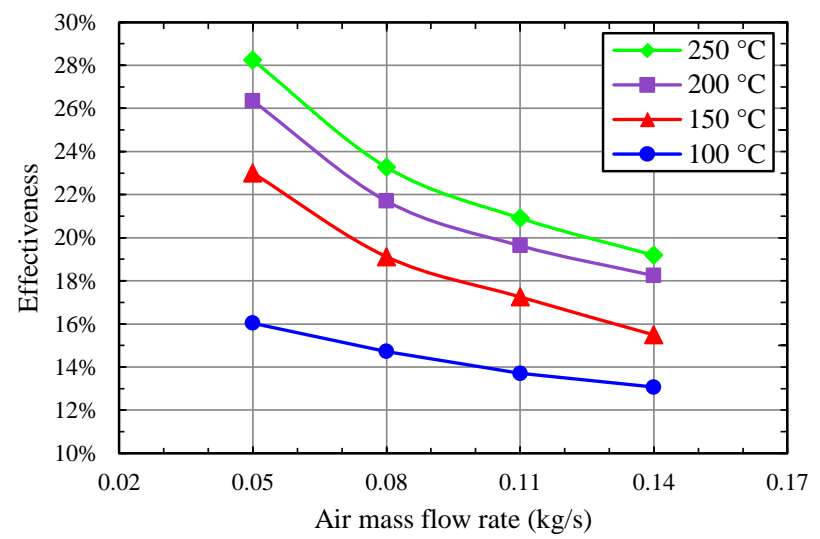

Figure 20 - Relation between the effectiveness of the heat exchanger and the incoming evaporator side conditions.

Figure 20 also illustrates how the effectiveness increases with the increase in the air inlet temperature. Increasing the air inlet temperature results in an increase in the temperature change in the cold side and therefore an increase in the effectiveness of the exchanger. The maximum effectiveness achieved was $28.24 \%$ at $0.05 \mathrm{~kg} / \mathrm{s}, 250^{\circ} \mathrm{C}$ which means that higher temperatures result in higher effectiveness but higher mass flow rates result in lower effectiveness. 


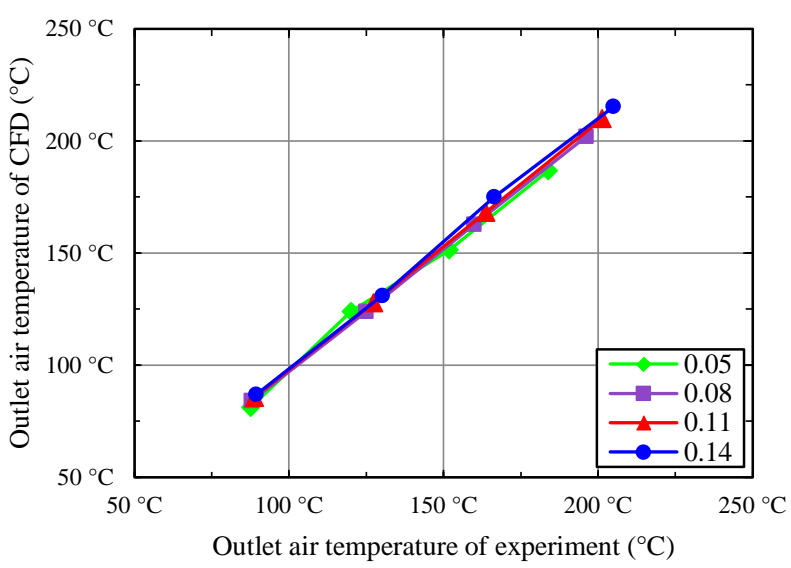

Figure 21 - Comparison between experimental and CFD results for the temperature at the outlet of the evaporator.

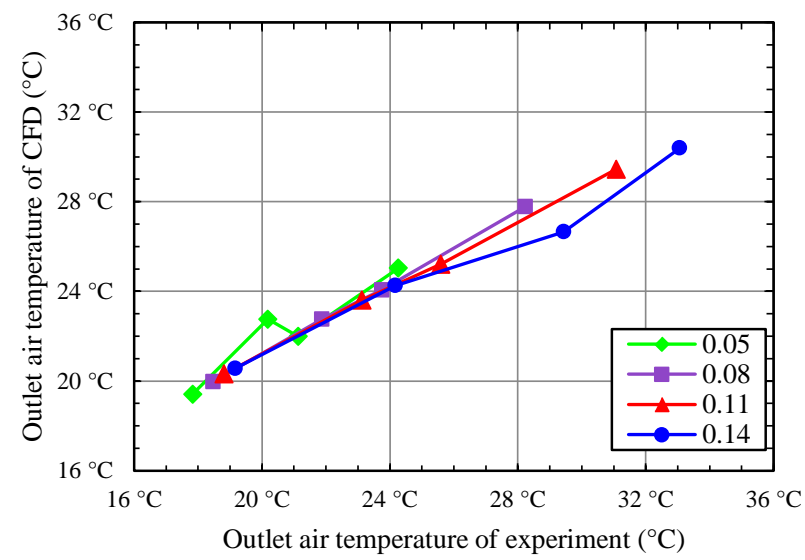

Figure 22 - Comparison between experimental and CFD results for the temperature at the outlet of the condenser.

Figure 21 and 22 show a direct comparison between the results of the experiment and the CFD for both the evaporator section and the condenser section, respectively. It is observed that the CFD simulation under-predicts the performance of the heat pipes at higher mass flow rates but overpredicts it at lower mass flow rates. This could possibly be improved by a minor update on the equation governing the conductivity of the pipe, especially in the boiling region.

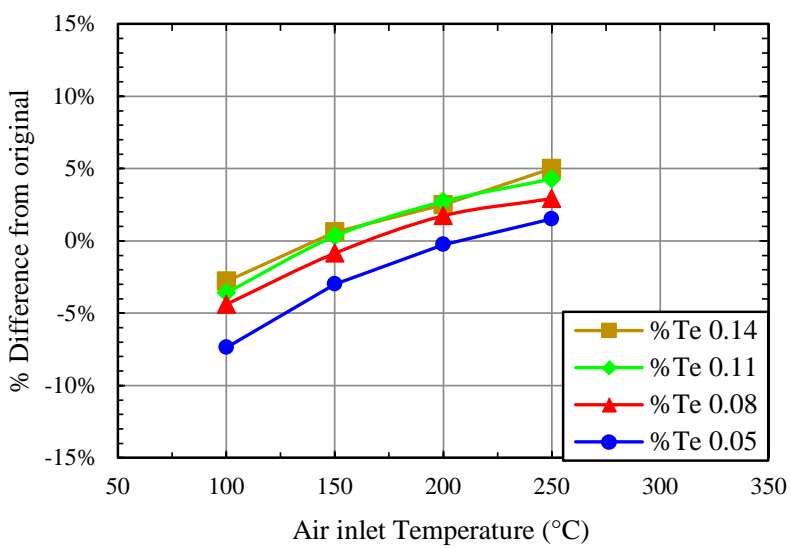

Figure 23 - Percentage difference between the experimental and the CFD results for the evaporator section for different inlet conditions. 


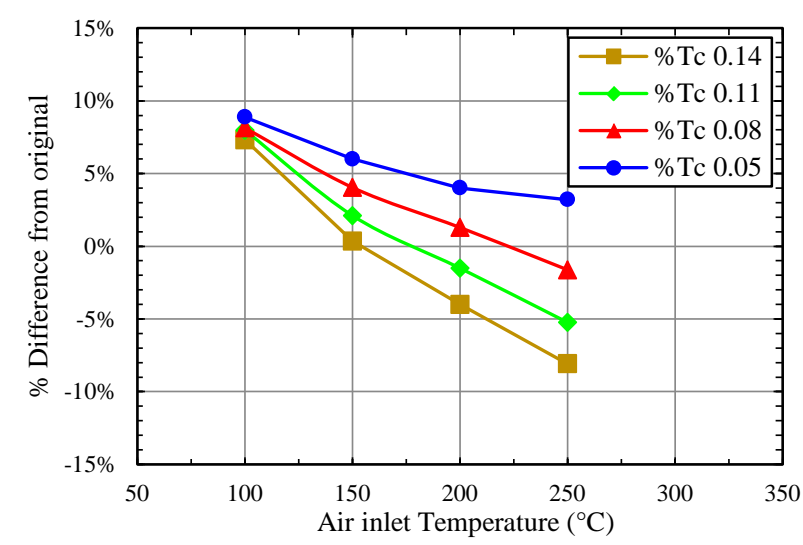

Figure 24 - Percentage difference between the experimental and the CFD results for the condenser section for different inlet conditions.

A more direct comparison between the experimental and CFD simulation results is presented in Figure 23 and 24 . All the predictions fall into a 10\% envelope, the most accurate ones being the test done at more average conditions. The evaporator side shows an upward trend, where the governing equation for the heat pipe's conductivity over predicts the conductivity at lower air inlet temperatures, but as the inlet temperature increases, it starts under-predicting it. The condenser section has a similar behaviour, but inverted. Overall, there is a very good agreement between the CFD, the empirical correlations and the experimental data (10\%).

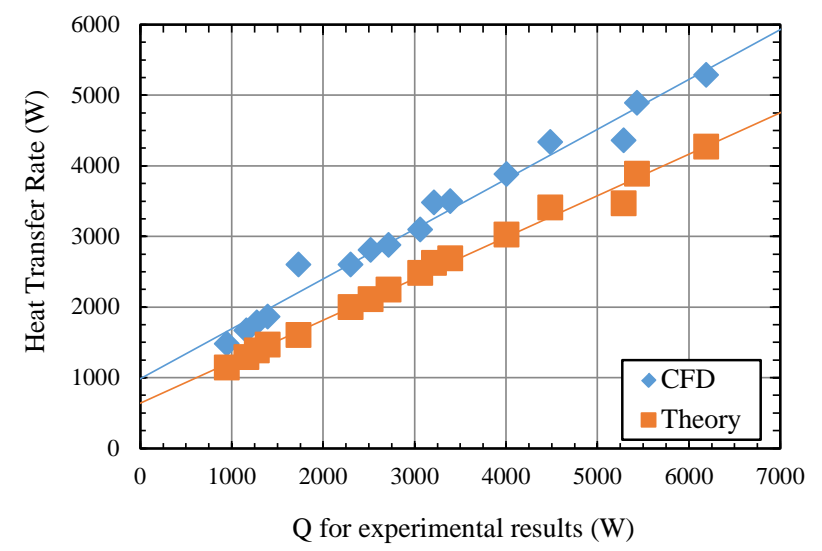

Figure 25 - Comparison of the total heat transfer rate value for the CFD results, the empirical correlations and the experimental data.

Figure 25 represents a direct comparison between the total heat transfer rate $(\mathrm{Q})$ obtained for the experimental rig during testing (through $Q=\dot{m} c_{p} \Delta T$ ) and the corresponding total heat transfer rate predicted by both the CFD simulation and equations found in literature for the same inlet conditions. Looking at the figure, the CFD software seems to over-estimate the performance of the heat exchanger at lower heat transfer rates (given by at lower inlet mass flow rate and temperatures) and under-estimating as the inlet conditions improve, as can be seen from the blue trend line created by the rhombuses. This pattern is in agreement with Figure 18 and 19. Overall there is good agreement between the experimental results and the CFD.

The prediction provided by the empirical correlations is very conservative, as is shown by the trend line formed by the red squares; it under-estimates the performance of the heat exchanger at all times. This may be a result of the equations used for convection from the flow to the pipe, as the same inner resistance for the pipes was used for both the CFD and the literature. 


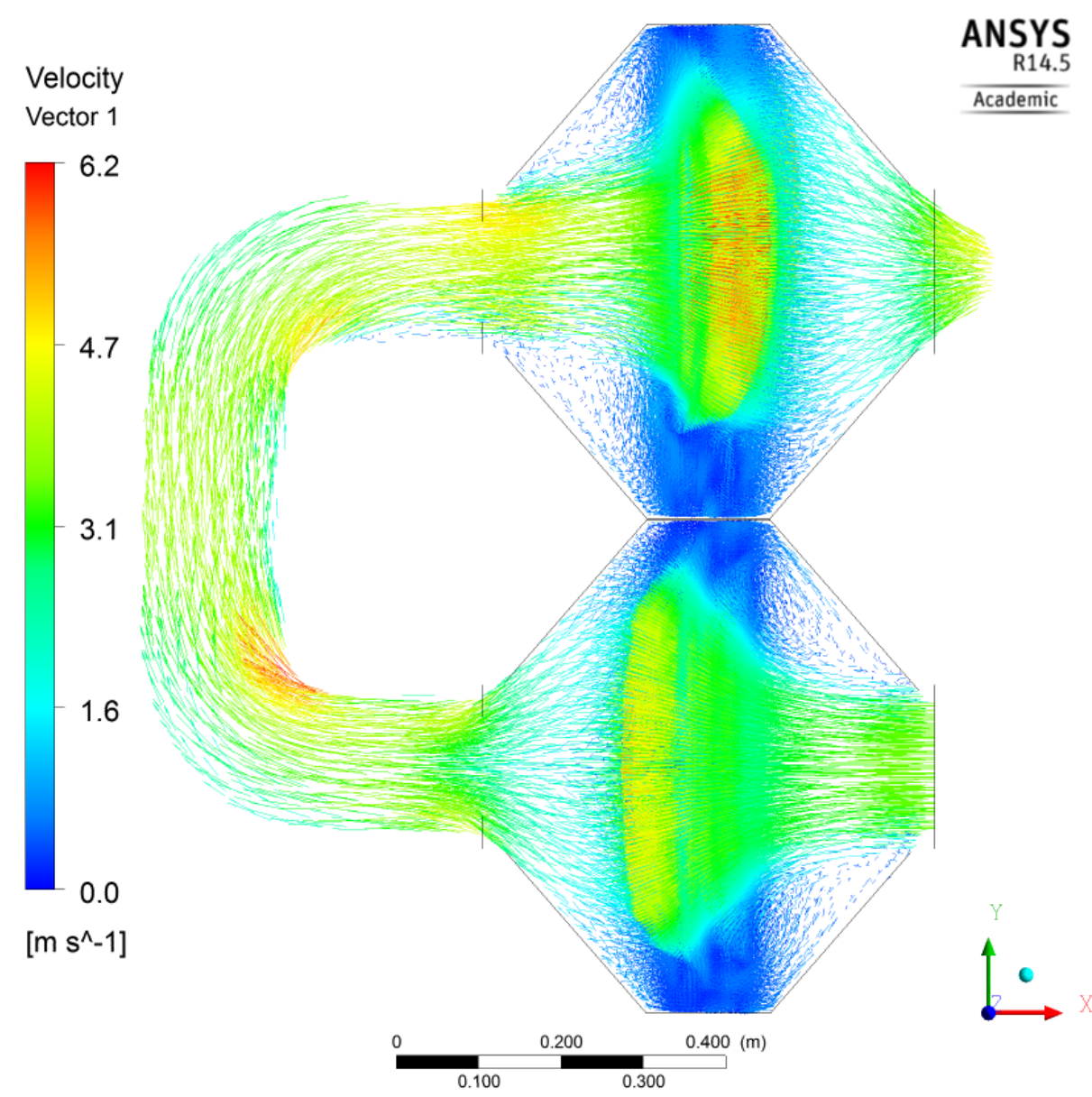

Figure 26 - Vector velocity plot of the evaporator section.
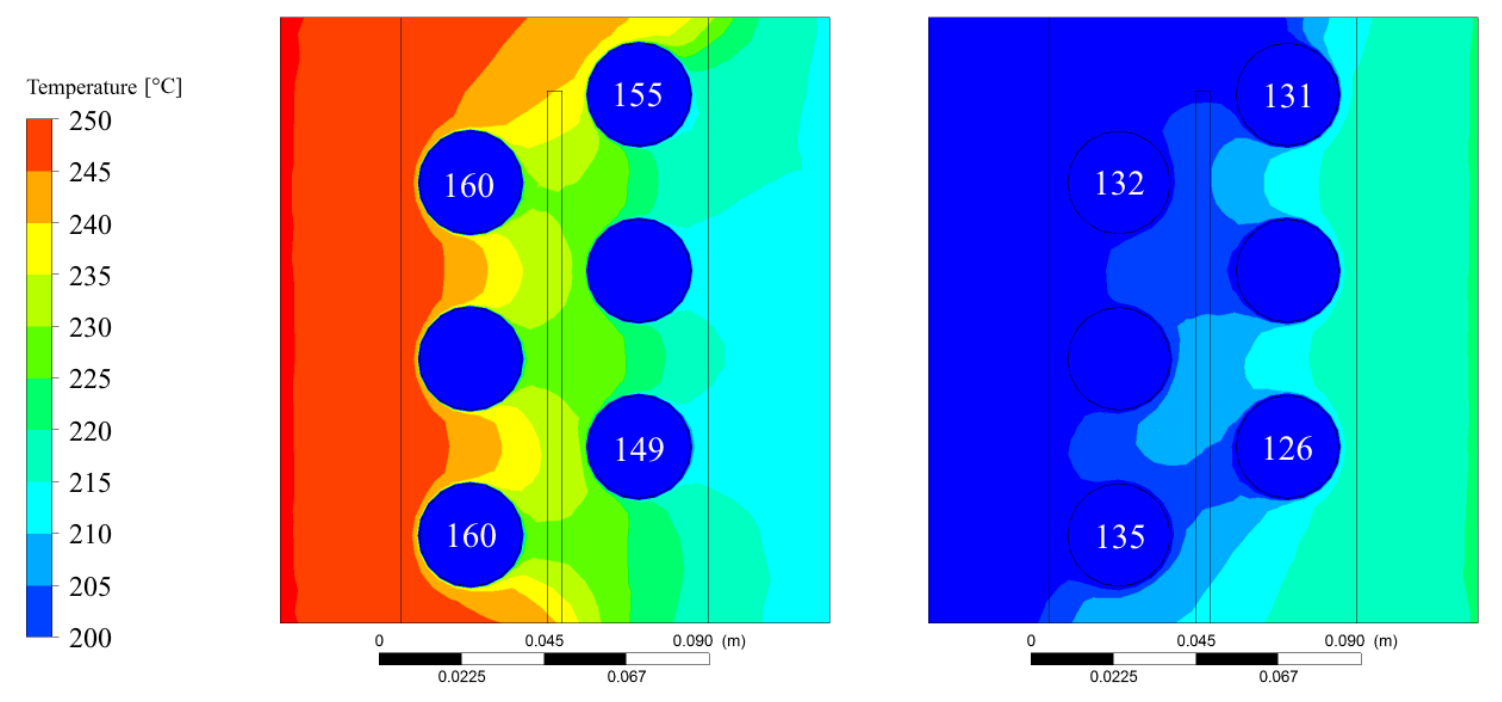

Figure 27 - Temperature contour of the evaporator section in the first $(\mathrm{y}=0.3 \mathrm{~m})$ and second $(\mathrm{y}=0.9 \mathrm{~m})$ air pass at $250^{\circ} \mathrm{C}$ and $0.14 \mathrm{~kg} / \mathrm{s}$.

Figure 26 illustrates a vector plot of the velocity inside the evaporator section of the heat exchanger showing the higher velocity zones at the bends. Figure 27 illustrates the temperature contours of the evaporator section in the first and second air passes. The air enters the heat exchanger at $250{ }^{\circ} \mathrm{C}$ from the left of the first pass and then flows through a u-shaped bend (at $220^{\circ} \mathrm{C}$ ) that leads it to the second 
air-pass, represented on the right side of the figure, leaving the evaporator at $200{ }^{\circ} \mathrm{C}$. The numbers inside the pipes represent the temperatures of the solid rods at the specified height (in ${ }^{\circ} \mathrm{C}$ ). As it can be easily discerned, the solid rods are not isothermal throughout their length as a thermosyphon would be; their temperature varies with the height due to the different fluid temperatures surrounding the pipes. However, their average temperature closely matches the saturation temperature of the pipes.
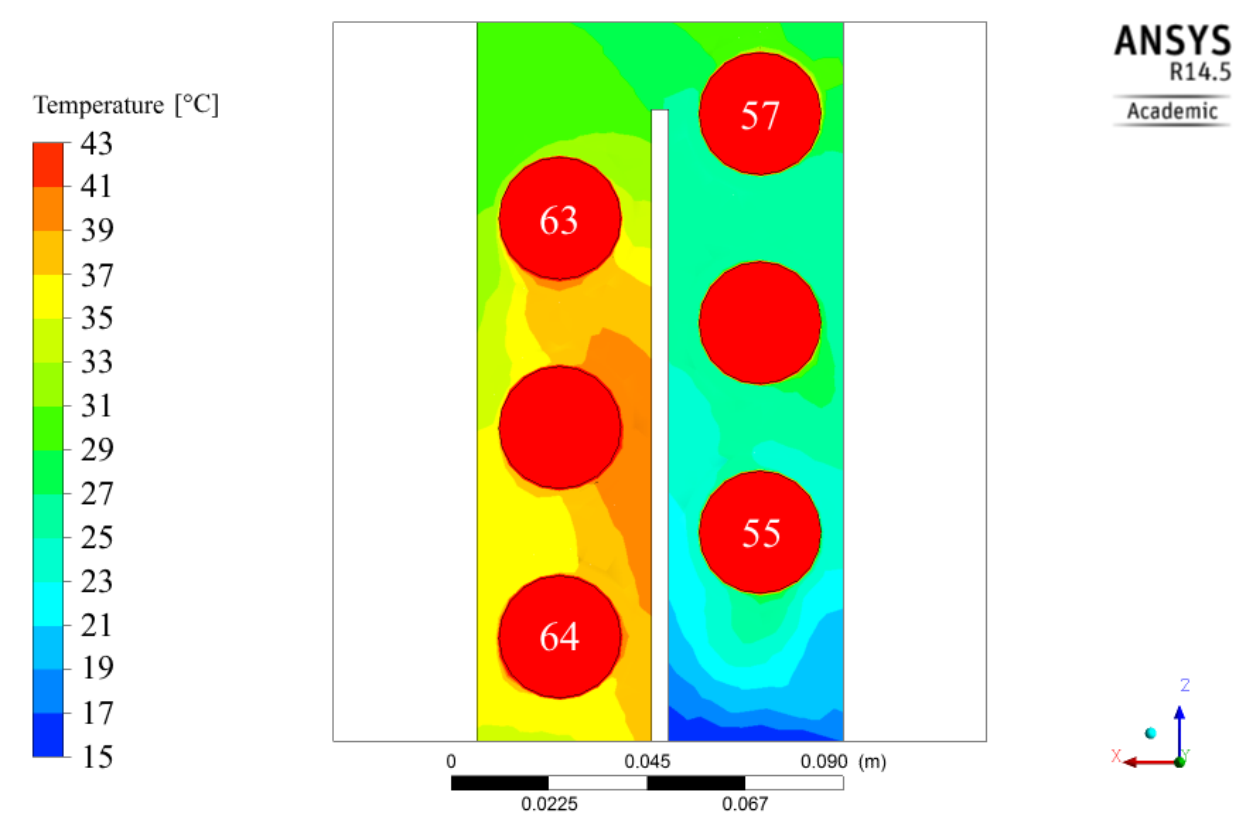

Figure 28 - Temperature contour of the condenser $(y=1.9 \mathrm{~m})$ at $250^{\circ} \mathrm{C}$ and $0.14 \mathrm{~kg} / \mathrm{s}$.

A temperature profile of the condenser is displayed in Figure 28. The water enters the condenser at a temperature of $15{ }^{\circ} \mathrm{C}$ and reaches a temperature of approximately $35{ }^{\circ} \mathrm{C}$ at the condenser outlet. The numbers in the pipes represent the temperature of the solid rods at that height. The temperatures keep the consistency shown in Figure 27 where the pipe closer to the inlet of the condenser displays the lower temperature.

\section{Error Analysis}

No physical quantity can be measured with certainty and measurements always contain errors. Errors can propagate through an experimental procedure due to many factors mainly human error, equipment usage and inaccurate experiment set-up. Effectiveness $(\varepsilon)$ was studied to investigate the error analysis. The uncertainty analysis of the effectiveness was calculated using the following equations [26]:

$$
\begin{gathered}
\mathrm{S}_{\dot{\mathrm{Q}}_{\mathrm{c}}}=\dot{\mathrm{Q}}_{\mathrm{c}} \sqrt{\left(\frac{\mathrm{S}_{\mathrm{FR}_{\mathrm{w}}}}{\mathrm{FR}_{\mathrm{w}}}\right)^{2}+\left(\frac{\mathrm{S}_{\Delta \mathrm{T}_{\mathrm{c}}}}{\Delta \mathrm{T}_{\mathrm{c}}}\right)^{2}} \\
\mathrm{~S}_{\Delta \mathrm{T}_{\text {max }}}=\sqrt{\left(\mathrm{S}_{\mathrm{T}_{\mathrm{h}, \mathrm{i}}}\right)^{2}+\left(\mathrm{S}_{\mathrm{T}_{\mathrm{c}, \mathrm{i}}}\right)^{2}} \\
\mathrm{~S}_{\Delta \mathrm{T}_{\mathrm{c}}}=\sqrt{\left(\mathrm{S}_{\mathrm{T}_{\mathrm{c}, \mathrm{o}}}\right)^{2}+\left(\mathrm{S}_{\mathrm{T}_{\mathrm{c}, \mathrm{i}}}\right)^{2}}
\end{gathered}
$$

Figure 29 shows how the percentage error of the effectiveness varies with the change in the inlet air mass flow rate for different inlet temperatures. It is obvious from the graph that the propagated error associated with the calculated effectiveness is inversely proportional to both mass flow rate and the 
inlet temperature. The greatest error came from the reading of the thermocouples at lower temperatures, more specifically at $10 \mathrm{~Hz}$. Figure 29 shows an inversely proportional relationship between the uncertainty for the effectiveness and temperature change, which explains why the maximum uncertainties were achieved at low inlet temperature because the temperature change is very small. For most engineering applications, a 10\% error is often considered acceptable [26].

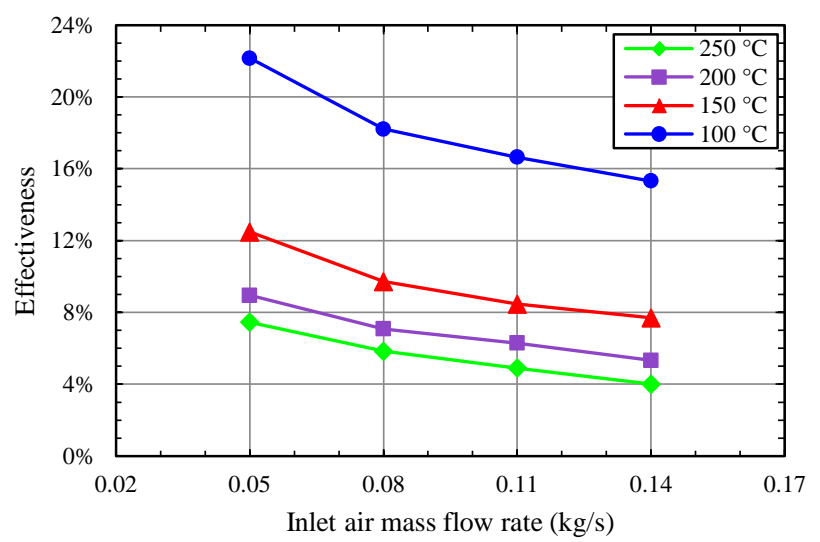

Figure 29 - Uncertainty analysis for the effectiveness.

\section{Conclusion}

An experimental and analytical investigation of a heat pipe-based heat exchanger with two air-passes was successfully carried out, its thermal performance analysed by a combination of several techniques including effectiveness and heat transfer rate. The results were analysed using expressions from recent literature and verified through modified correlations to ensure the heat balance had been achieved. Inlet conditions used in the experiment such as mass flow rate, inlet temperature and thermal conductivity have been converted into boundary conditions that were then used in the numerical modelling of the heat exchanger. The following conclusions were drawn from the experimental and numerical results:

- Higher heat transfer rate was achieved at higher inlet temperatures and mass flow rates;

- Effectiveness was found to be proportional to the air inlet temperature and inversely proportional to the inlet air mass flow rate;

- A maximum effectiveness of $29 \%$ was achieved at the lowest air flow rate and maximum inlet temperature;

- A higher heat transfer rate was achieved in the first pass than in the second pass, a fact demonstrated both experimentally and numerically;

- Good agreement has been found between the experimental and numerical results for all the outlet temperatures;

- An average temperature difference of 3\% was observed between the experimental and numerical results in the evaporator section and an average difference of $5 \%$ in the condenser side.

\section{Acknowledgements}

The work has been funded by Econotherm (UK) Ltd, an associate company of Spirax Sarco PLC. 


\section{Nomenclature}

$\begin{array}{lll}A & \left(\mathrm{~m}^{2}\right) & \text { Heat transfer area } \\ C & (\mathrm{~W} / \mathrm{K}) & \text { Heat capacity rate } \\ C_{r} & (-) & \text { Ratio of heat capacities } \\ c_{p} & (\mathrm{~J} /(\mathrm{kg} . \mathrm{K})) & \text { Specific heat capacity } \\ C_{s f} & (-) & \text { Coefficient of liquid/surface combination } \\ h & \left(\mathrm{~W} /\left(\mathrm{m}^{2} . \mathrm{K}\right)\right. & \text { Heat transfer coefficient } \\ h_{f g} & (\mathrm{~J} / \mathrm{kg}) & \text { Specific enthalpy of evaporation / latent heat of vaporisation } \\ K_{p} & (-) & \text { Dimensionless parameter } \\ k & (\mathrm{~W} /(\mathrm{m} . \mathrm{K})) & \text { Constant of thermal conductivity } \\ l & (\mathrm{~m}) & \text { Length } \\ \dot{m} & (\mathrm{~kg} / \mathrm{s}) & \text { Mass flow rate } \\ N u & (-) & \text { Nusselt number } \\ P r & (-) & \text { Prandtl number } \\ \dot{Q} & (\mathrm{~W}) & \text { Heat transfer rate } \\ \dot{q} & (\mathrm{~W}) & \text { Local heat transfer rate } \\ R & (\mathrm{~K} / \mathrm{W}) & \text { Thermal resistance } \\ r & (\mathrm{~m}) & \text { Radius of cylinder } \\ R e & (-) & \text { Reynolds number } \\ T & \left({ }^{\circ} \mathrm{C}\right) & \text { Temperature } \\ \bar{T} & \left({ }^{\circ} \mathrm{C}\right) & \text { Average temperature } \\ \Delta T & \left({ }^{\circ} \mathrm{C}\right) & \text { Difference in temperature } \\ U & \left(\mathrm{~W} /\left(\mathrm{m}^{2} . \mathrm{K}\right)\right) & \text { Overall heat transfer coefficient } \\ \varepsilon & (-) & \text { Effectiveness } \\ \mu & (\mathrm{Pa} . \mathrm{s}) & \text { Dynamic viscosity } \\ \rho & \left(\mathrm{kg} / \mathrm{m}^{3}\right) & \text { Density } \\ \sigma & (\mathrm{N} / \mathrm{m}) & \text { Surface tension } \\ & & \end{array}$

\section{Subscripts}

$b \quad$ Boiling

c Condenser side

$h$ Convection

$e \quad$ Evaporator side

$h p \quad$ Heat pipe / thermosyphon

$i \quad$ Inlet

$k \quad$ Conduction

$L \quad$ Liquid phase

LM Logarithmic mean

$n \quad$ Number of pipes

o Outlet

$r \quad$ Rate

$T \quad$ Total

$V \quad$ Vapour phase

w Water

6hp For 6 heat pipes

\section{Abbreviations}

CFD Computational Fluid Dynamics

$k-\varepsilon \quad$ k-epsilon turbulence method

NTU Number of Transfer Units

TPCT Two-phase closed thermosyphons 


\section{References}

[1] Grubb M, Vrolijk C, Brack D, Energy and Environmental Programme (Royal Institute of International Affairs). The Kyoto Protocol: A Guide and Assessment. Energy and Environmental Programme, Royal Institute of International Affairs, 1999.

[2] Steffen W, Noble I, Canadell J, Apps M, Schulze ED, Jarvis PG. The terrestrial carbon cycle: implications for the Kyoto Protocol. Science 1998;280(5368):1393-4.

[3] Reay D, Harvey A. The role of heat pipes in intensified unit operations. Applied Thermal Engineering 2013 Aug;57(1-2):147-53.

[4] Reay DA, Kew PA, McGlen RJ. Chapter 6 - Special types of heat pipe. In: Reay DA, Kew PA, McGlen RJ, editors. Heat Pipes (Sixth Edition).Oxford, Butterworth-Heinemann, 2014: p. 13573.

[5] Chang FL, Hung YM. The coupled effects of working fluid and solid wall on thermal performance of micro heat pipes. International Journal of Heat and Mass Transfer 2014 Jun;73(0):76-87.

[6] Teke A, Timur O. Assessing the energy efficiency improvement potentials of HVAC systems considering economic and environmental aspects at the hospitals. Renewable and Sustainable Energy Reviews 2014 May;33(0):224-35.

[7] Wang Z, Yang W. A review on loop heat pipe for use in solar water heating. Energy and Buildings 2014 Aug;79(0):143-54.

[8] Jouhara $\mathrm{H}$, Anastasov $\mathrm{V}$, Khamis I. Potential of heat pipe technology in nuclear seawater desalination. Desalination 2009 Dec 25;249(3):1055-61.

[9] Reay DA, Kew PA, McGlen RJ. Chapter 7 - Applications of the heat pipe. In: Reay DA, Kew PA, McGlen RJ, editors. Heat Pipes (Sixth Edition).Oxford, Butterworth-Heinemann, 2014: p. 175206.

[10] Bai L, Lin G, Zhang H, Miao J, Wen D. Operating characteristics of a miniature cryogenic loop heat pipe. International Journal of Heat and Mass Transfer 2012 Dec;55(25ГÇô26):8093-9.

[11] Laubscher R, Dobson RT. Theoretical and experimental modelling of a heat pipe heat exchanger for high temperature nuclear reactor technology. Applied Thermal Engineering 2013 Nov 3;61(2):259-67.

[12] Jouhara H, Robinson AJ. Experimental investigation of small diameter two-phase closed thermosyphons charged with water, FC-84, FC-77 and FC-3283. Applied Thermal Engineering 2010 Feb;30(2ГÇô3):201-11.

[13] Kim MS, Lee KS, Song S. Effects of pass arrangement and optimization of design parameters on the thermal performance of a multi-pass heat exchanger. International Journal of Heat and Fluid Flow 2008 Feb;29(1):352-63.

[14] Incropera FP, David PD. Chapter 7 - External Flow. Fundamentals of Heat and Mass Transfer. 4th Edition ed. New York, John Wiley \& Sons, 1996: p. 377-86. 
[15] Danielewicz J, Sayegh MA, +Üniechowska B, Szulgowska-Zgrzywa M, Jouhara H. Experimental and analytical performance investigation of air to air two phase closed thermosyphon based heat exchangers. Energy(0).

[16] Jouhara $H$, Merchant $H$. Experimental investigation of a thermosyphon based heat exchanger used in energy efficient air handling units. Energy 2012 Mar;39(1):82-9.

[17] Reay DA, Kew PA, McGlen RJ. Chapter 3 - heat pipe componants and materials. In: Reay DA, Kew PA, McGlen RJ, editors. Heat Pipes (Sixth Edition).Oxford, Butterworth-Heinemann, 2014: p. 88-9.

[18] Fluent Inc. FLUENT 6.3 User's Guide. 2014.

[19] M.Thirumaleshwar. Fundamentals of Heat and Mass Transfer. Pearson Education, 2009.

[20] ESDU 81038. Heat pipes - performance of two-phase closed thermosyphon. 1983.

[21] Rohsenow WM, Hartnett JP. Chapter 13 - Boiling. Handbook of heat transfer.New York, McGraw-Hill, 1973.

[22] El-Genk MS, Saber HH. Heat transfer correlations for small, uniformly heated liquid pools. International Journal of Heat and Mass Transfer 1998 Jan;41(2):261-74.

[23] Incropera FP, David PD. Chapter 10 - Boiling and Condensation. Fundamentals of Heat and Mass Transfer. 4th Edition ed. New York, John Wiley \& Sons, 1996: p. 535-80.

[24] McAdams WH. Heat Transmission. 1954.

[25] Jouhara H, Meskimmon R. Experimental investigation of wraparound loop heat pipe heat exchanger used in energy efficient air handling units. Energy 2010 Dec;35(12):4592-9.

[26] Taylor JR. An Introduction to Error Analysis: The Study of Uncertainties in Physical Measurements. University Science Books, 1997. 